\title{
13
}

\section{Electoral Design, Sub-Majority Rules, and Representation for Future Generations}

\author{
Kristian Skagen Ekeli
}

\subsection{The Proposal}

The purpose of this chapter is to present and consider two alternative models for political representation of future generations. The aim of these models is to promote more future-oriented deliberations and decisions in representative democracies, and to create more public awareness and engagement about important political issues that can have a serious impact on the living conditions of near and distant future generations. The first model has been proposed by Andrew Dobson, and it can be called the restricted franchise model. ${ }^{1}$ According to this model, some seats in legislative assemblies should be reserved for special representatives of future generations (hereafter F-representatives), who should be granted the same lawmaking powers as ordinary legislators in majority rule legislatures. These special representatives should be elected, but the rights (a) to elect F-representatives and (b) to serve as F-representatives are restricted to what Dobson calls the 'environmental sustainability lobby' (i.e. environmental groups and organizations).

The second model, which I have recently proposed, can be termed the submajority rule model. ${ }^{2}$ According to this model, a minority of at least one-third of the legislators should be granted two procedural rights in order to protect future interests. The first empowers a minority to delay legislation, while the second grants a minority the right to require referendums. In contrast to Dobson's model, my proposal implies that legislators are selected and accountable through ordinary periodic elections, where the whole electorate

\footnotetext{
${ }^{1}$ See Dobson $1996 . \quad{ }^{2}$ See Ekeli 2009.
} 
can participate on equal terms. However, the sub-majority rule model grants special procedural rights to legislators who are elected and accountable in this way. More precisely, the model gives the right to require delays and referendums to any predefined numerical minority of future-oriented legislatorsthat is, legislators who are concerned for the welfare of near and distant future generations, and who wish to prevent laws that they (sincerely or in good faith) believe have a serious negative impact on posterity.

Dobson's model and my proposal differ along at least five dimensions, and some of these are related. ${ }^{3}$

(1) The representatives: Who should be empowered to serve as representatives of future generations in elections and legislatures? Who should be granted special powers to represent and protect future interests in legislatures?

(2) Selection of representatives: How should the representatives be selected?

(3) Accountability mechanisms: How should the representatives be held accountable, and by whom (i.e. who should be the accountabilityholders)?

(4) Powers: What powers should the representatives have?

(5) Voting rules in the legislature: What voting rules should be used in the legislature-only majority rule (Dobson's model) or a combination of majority rule and sub-majority rule (my proposal)?

As compared to the status quo (i.e. existing representative democratic institutions), I believe that these two models can, in different ways, serve as useful political tools to promote more future-oriented political deliberations and decisions in representative democracies. However, I will argue that the submajority rule model has some important advantages compared with the restricted franchise model. More precisely, my proposal has more far-reaching and desirable effects with regard to processes of agenda-setting, deliberation, exchange of information, and citizen involvement. The sub-majority rule model also provides a better future-oriented system of checks and balances.

This chapter proceeds as follows. In section 13.2, I will present and consider Dobson's restricted franchise model. Section 13.3 presents the sub-majority rule model and sets out a case for this proposal.

\subsection{The Restricted Franchise Model}

Dobson's proposal is that some seats in legislative assemblies should be reserved for special representatives of future generations. This model has two

\footnotetext{
${ }^{3}$ More precisely, (1), (2), and (3) are related and (4) and (5) are related.
} 


\section{Kristian Skagen Ekeli}

important aspects. The first concerns the powers of the F-representatives. These representatives should have the same powers as ordinary legislators in majority rule legislatures. First, they have proposal rights-that is, the power to place bills on the formal voting agenda in the legislature. Secondly, they should be granted lawmaking competence-that is, the power to vote for or against laws in a legislature using majority rule. Unfortunately, Dobson does not specify how many seats the F-representatives should have. For present purposes, I will, however, assume that for instance 5 or 10 per cent of the seats are reserved for these special representatives.

The second aspect of the restricted franchise model concerns electoral design and Dobson's mechanism of proxy accountability. The F-representatives should be elected. However, the rights (a) to elect F-representatives and (b) to serve as F-representatives are restricted to what Dobson calls the 'environmental sustainability lobby' (i.e. environmentalists or environmental groups and organizations). According to Dobson, the sustainability lobby should function as proxy or substitute future generations. More precisely, environmentalists should function as a proxy electorate (i.e. a proxy constituency) from which proxy candidates can be drawn or selected, and these candidates have the right to run for parliament and to serve as F-representatives if elected. ${ }^{4}$ This electoral system and its rationale will be discussed more closely in this chapter.

With regard to the assessment of the restricted franchise model, a central question is whether this model provides a reasonably effective and desirable way to represent and protect future interests compared with the status quothat is, existing representative democratic institutions. In what follows, I will first set out some important arguments in support of this model (sections 13.2.1 and 13.2.2). Thereafter, I will present some of the problems it faces (section 13.2.3).

\subsubsection{Electoral Design, Proxy Accountability, and Representative Legitimacy}

The aim of mechanisms of accountability characteristic of representative democracies is to induce representatives to act in the best interests of the represented. In representative democracies, periodic elections are important vertical accountability mechanisms, because they give the electorate-i.e. the accountability-holders-the ability and power to impose sanctions or costs on their representatives if they fail to act in what the voters believe is in their best interest. The way periodic elections are designed in existing representative

\footnotetext{
${ }^{4}$ See Dobson 1996: 132.
} 
democracies is, however, not necessarily a good mechanism of accountability for inducing legislators to act in the best interest of future citizens. Future generations cannot authorize representatives/legislators to act on their behalf; nor can they hold them accountable by punishing or rewarding them during elections. Since legislators are merely accountable to present citizens, politicians and political parties will in many cases have strong incentives not to take a position that deviates too much from the preferences or short-term interests of their voters, in order to avoid being punished during elections. In this way, politicians who want to be (re-)elected depend on an electorate which is in many cases short-sighted and impatient, and this can create strong incentives to over-discount the future in political decision-making processes.

Dobson's design of the restricted franchise model is an attempt to overcome this problem of myopia-the problem of the short-sightedness of the electorate and politicians. With regard to elections of F-representatives, his solution to the problem of myopia represents a new and interesting answer to the question of who the accountability-holders should be. Dobson assumes that the proxy (i.e. environmentalists) should be the accountability-holders in elections of F-representatives, because they are adequately motivated in the sense that they can be presumed to have the interests of future generations at heart. It can be argued that there are two sources of the proxy's representative legitimacy. The first is that the proxy is presumed to care for the well-being of posterity. The second is that the proxy has knowledge or expertise about environmental issues.

As compared to the status quo, one can argue that Dobson's system of proxy accountability has two advantages. First, given the care and knowledge (or expertise) of environmentalists, Dobson assumes that the proxy electorate will elect F-representatives that they believe will protect the interests of future generations. If F-representatives fail to do a good job, the proxy constituency will punish them during elections, because these accountability-holders are adequately motivated when they evaluate the performance of the F-representatives. Second, this mechanism of proxy accountability will create strong incentives for the F-representatives to act in the interest of future generations (or what they believe is in their best interest) while holding office.

\subsubsection{Agenda-Setting and Deliberation}

As compared to the status quo, one important argument in support of having special representatives of posterity in the legislature is that they can play a central role in processes of agenda-setting and deliberation.

(1) Agenda-setting: F-representatives can have positive effects with regard to processes of agenda-setting especially in legislatures, because they are 


\section{Kristian Skagen Ekeli}

empowered to place issues on the formal voting agenda. The special representatives can also create more public awareness about important environmental issues affecting future generations. In this connection, Dobson's hope is presumably that a 'representative can be an advocate who turns the whole nation, not merely the assembly, into a public forum. The representative is an intermediary who can expand the space for political discussion beyond governmental institutions and at the same time bring political decisions to the people's attention for scrutiny., ${ }^{5}$

(2) The deliberative value of special F-representatives: Special F-representatives can promote more well-informed processes of deliberation in legislatures, and the hope is that this can contribute to more future-oriented decision outcomes. First, the F-representatives get the opportunity to present proposals, arguments and perspectives that might not have been introduced and taken into consideration in the absence of special representatives. Secondly, the F-representatives can make relevant information (about values, facts, problems, solutions, and options) available in the legislature. To the extent that they play this role, this will improve the basis of information among decision-makers. With regard to processes of deliberation, it should be noted that the number of F-representatives and their voting power are of secondary importance compared to the value of representing arguments and making relevant information available in legislative assemblies.

\subsubsection{Problems Facing the Restricted Franchise Model}

Although something can be said for Dobson's model as compared to the status quo, it faces some important problems. The first is that the restricted franchise model is in conflict with the democratic ideal of 'one person, one vote', since it gives the members of the proxy electorate two votes each, while the rest of the electorate only has one. The proxy electorate can cast one vote for F-representatives and one for ordinary representatives. As Dobson points out, it is possible to revise the model in order to avoid this problem:

One way of catering for this might be to deprive the proxy generation of its vote for the present generation and leave it with a vote for future generations.... The sustainability lobby might be prepared to accept such an arrangement in respect of the following thought: that a vote for future generations is also (largely but not wholly) a vote for a particular type of present politics-the sustainability politics for which they would vote if they had not forgone the right to do so. ${ }^{6}$

\footnotetext{
${ }^{5}$ Urbinati 2000: 766-7. $\quad{ }^{6}$ Dobson 1996: 134.
} 
Dobson's response might solve this problem, but his model is still open to other objections.

A second line of criticism is that the restricted franchise model seems to close off both reasonable disagreement and debate about the controversial issue of who should be empowered to serve as representatives for future generations-in the sense that it gives one particular group or movement (i.e. the environmental sustainability lobby) with a restricted range of perspectives the privileged status of representative for future generations in advance of public deliberation. In a representative deliberative democracy, this seems to be problematic. ${ }^{7}$ First, environmentalists are not alone in caring for the well-being of near and distant future generations. Second, the intergenerational issues we face today do not only concern the environment, but also other political issues (e.g. budget deficits and public pension plans). Third, in a number of cases, there exist reasonable disagreements about what is in the best interests of posterity, and it is by no means obvious that environmentalists have a privileged access to the 'truth' in such matters. Even if one agrees that there is a need for new forms of representation of posterity, one can reject the idea that one 'lobby' (or interest group) should have special representatives in the legislature who are both drawn from this lobby/interest group and elected by its members.

The next problem concerns the effectiveness of Dobson's model with regard to the F-representatives' ability and power to police, control, and sanction myopic majorities in the legislature. The F-representatives have very limited ability and power to check and balance the power of majorities who want to make hasty and short-sighted decisions. Thus, as a system of checks and balances, the model has limited value (I will return to this issue in the next section). This does not mean that the F-representatives' limited voting power has no value in order to affect or influence decision outcomes. Under certain circumstances, the F-representatives can play a central role in coalitionbuilding in majority rule legislatures. For example, they can trade votes on issues they consider of minor importance in order to gain support on issues they regard as vital.

\subsection{The Sub-Majority Rule Model}

The aim of the sub-majority rule model is to give minorities of legislators, who are selected and accountable through ordinary periodic elections, certain political tools to represent and protect the interests of future generations.

\footnotetext{
7 This problem is discussed in more detail in Ekeli 2005: 435-7.
} 


\section{Kristian Skagen Ekeli}

The common denominator of the proposed reforms is that they represent examples of what can be termed sub-majority rules. In a recent interesting analysis of sub-majority rules, Adrian Vermeule points out that a sub-majority rule is 'a voting rule that authorises (i) a predefined numerical minority within a designated voting group (ii) to change the status quo (not merely to prevent change) (iii) regardless of the distribution of other votes' ${ }^{8}$ According to Vermeule, sub-majority rules are rarely or never used directly for final substantive decisions, such as the passage or defeat of legislation. Rather, they are used for procedural matters-for example, to set procedures and agendas for public deliberation and voting. This also applies to the proposed sub-majority rules, which can be regarded as procedural rights ascribed to predefined minorities of legislators.

\subsubsection{The Right of Minorities to Require Delays}

A minority of at least one-third of the legislators should be granted the right to require that the final enactment of a law proposal should be delayed until a new election has been held, if they believe that the law in question can inflict serious harm upon posterity. This means that a minority has the power to demand that the bill can only be enacted after an intervening election.

\subsubsection{The Right of Minorities to Require Referendums}

A minority of at least one-third of the legislators should be granted the right to demand a referendum on a bill that can have a serious adverse impact on the living conditions of future generations. Thus, a minority can place an issue before the people for final approval. With regard to this proposal, it is important that the electorate get sufficient time to gather relevant information, as well as to consider and discuss the bill. Therefore, there should be a time interval of a least one year from the minority's call for the referendum until it is held. However, in order to avoid a too time-consuming process, there should be a limit to the interval allowed-e.g. two years.

At this point, it is important to make three clarifications with regard to the sub-majority rules and their application. First, the sub-majority rules do not privilege any particular minority of legislators, who are selected through ordinary periodic elections where the whole electorate can participate on equal terms. Any predefined numerical minority of legislators will be given these tools, and the hope is that future-oriented legislators will use them in order to protect future interests. Second, a minority of legislators should only

\footnotetext{
8 Vermeule 2005: 76.
} 
be allowed to demand a delay or a referendum if they present a prima facie case for the assumption that the law proposal in question can inflict serious harm or risk upon posterity. Thereafter, the burden of proof should shift to those legislators who reject the minority's harm scenario. Third, conflicts about the reliability of competing harm scenarios should be resolved by a constitutional court (i.e. a special constitutional court or some similar body such as the state's supreme court), since such controversies involve issues of constitutional law (i.e. such conflicts concern the distribution of powers between minorities and majorities as specified in the constitution). In cases where controversies arise, the legislators who want to prevent a delay or a referendum (for instance 10 per cent of the legislators) should be allowed to initiate legal proceedings. But, as already pointed out, in such cases the onus of proof should rest with those who reject the minority's harm scenario after the minority has presented their prima facie case. It should, however, be underlined that when controversial cases are brought before a court, the court has the power to reject a delay or a referendum in cases where it does not find the prima facie case offered by the minority convincing-that is, if the court assumes that the law in question does not expose posterity to risks that can seriously harm their living conditions, or if the court suspects that a minority is abusing the sub-majority rules for strategic reasons. ${ }^{9}$

\subsubsection{The Case for the Sub-Majority Rule Model}

As compared to Dobson's model, I believe that the sub-majority rule model provides more effective and desirable political tools to represent and protect future interests. More precisely, my thesis is this. If future-oriented minorities use or can use the proposed procedural rights, the sub-majority rule model has more far-reaching and desirable effects than Dobson's model. The reason for this is that the sub-majority rules can have significant and extensive effects with regard to processes of agenda-setting, intrapersonal and interpersonal deliberation, ${ }^{10}$ exchange of information (i.e. distribution and dissemination of information), and citizen involvement. The sub-majority rule model also provides a better and more effective future-oriented system of checks and balances than the restricted franchise model.

\footnotetext{
${ }^{9}$ In view of uncertainty and disagreement about the future effects of present policies and the reliability of alternative future harm scenarios, judicial review on the basis of this aspect of the submajority rule model will give courts some degree of power in the lawmaking process. Such issues are discussed more closely in Ekeli 2007a.

${ }^{10}$ Interpersonal deliberation refers to the process of discussion with others or interpersonal communications-e.g. debates in legislatures. Intrapersonal deliberation refers to an individual's internal reflections (or considerations), for instance, on political issues-e.g. when we read a newspaper or watch a political discussion on TV and deliberate about the pros and cons of alternative policies.
} 


\section{Kristian Skagen Ekeli}

AGENDA-SETTING

The power to place issues on the formal political voting agenda and the procedural rights to determine how those issues are to be decided play an important role in political decision-making. The proposed sub-majority rules will affect the distribution of agenda-setting power, because they will to some extent have the effect of distributing the competence to control the agenda away from majorities to minorities. First, minorities are empowered to influence how long an issue should be on the agenda, and to decide how the issue should be placed on the formal voting agenda. In this way, minorities have the power to force the majority to pay more attention to certain issues affecting posterity. Second, the suggested procedural rights can give minorities of legislators the opportunity to increase the political visibility and the public awareness of important intergenerational issues. These points will be elaborated here.

\section{PROCESSES OF DELIBERATION}

An important aim of the proposed procedural rights is to improve the process of deliberation and decision-making about issues that can have a serious impact on the living conditions of posterity. The purpose is to improve the basis of information and enhance the level of reflection among legislators and voters. Dobson's model can, as we have seen, also have positive effects with regard to processes of deliberation, but one can argue that the sub-majority rule model can have more far-reaching effects.

In contrast to Dobson's model, both sub-majority rules empower futureoriented minorities to slow down the decision-making process. This means that the sub-majority rules can promote a more thorough and well-informed process of intrapersonal and interpersonal deliberation about certain issues or law proposals. First, to the extent that minorities use their right to demand delays or referendums, this will ensure that both the electorate and politicians have the opportunity to consider the proposals in question more closely before a decision is made through majority rule in legislatures or referendums. Second, in this process they will have time to gather and distribute new and relevant information which can in turn affect the subsequent process of deliberation, agenda-setting, and decision-making.

Third, if a minority requires a delay or a referendum, decision-makers will have more time to come up with, discuss, and consider alternative courses of action, which might have more desirable consequences with regard to future generations than the bills that were initially introduced. The hope is that this can initiate a dynamic educative process of public deliberation-where relevant decision-makers and publics are exposed to a diversity of ideas, proposals, and problems. Moreover, compared with decision procedures which make it possible to make more hasty and less visible collective decisions (i.e. the status 
quo in most democratic states ${ }^{11}$ ), the proposed decision rules can also improve the quality of collective decisions, since decision-makers (both citizens and legislators) are given a better opportunity to pool their knowledge, insight, and experience prior to voting. In these ways, the proposed procedural rights can lead to a process of intrapersonal and interpersonal deliberation that might lessen the problem of bounded rationality-the problem that our knowledge, imaginations, and reasoning abilities are limited and fallible.

\section{CITIZEN INVOLVEMENT}

The restricted franchise model only involves the proxy electorate (i.e. environmentalists) in elections of F-representatives - the rest of the electorate is excluded. As compared to Dobson's model and existing representative democracies, the proposed procedural rights can, as already indicated, induce more public awareness and engage citizens more directly when it comes to issues affecting future generations. First, if a minority requires a delay, this will ensure that the people have the opportunity to consider the law proposal more closely during election campaigns. Citizens will also be given the chance to determine the composition of the legislative assembly before the law proposal can be enacted through majority vote.

Second, a direct democratic device such as a referendum can provide a useful institutional mechanism for engaging citizens more directly in public deliberations about important intergenerational issues. In this connection, it is worth noting that referendums can change the demand for political information and the supply of it. ${ }^{12}$ On the demand side, referendums can increase the incentives of voters to gather information, partly as a result of more intense public discussions before the popular vote. On the supply side, referendums increase the incentives of politicians and the media to provide information. If politicians and interest groups want to win a referendum, they are forced to inform the public about the reasons why they are for or against the policy in question. During referendum campaigns, these political actors have to provide information on the issue at stake, and they must publicly discuss and critically scrutinize the arguments and information offered by their opponents.

\section{A FUTURE-ORIENTED SYSTEM OF CHECKS AND BALANCES}

Systems of checks and balances are usually introduced in order to guard against abuse of state power and despotism (or arbitrary use of state power). In constitutional democracies, one central aim of checks and balances is to provide a guard against the danger that the rulers (e.g. majorities of legislators) use the power that is conferred on them against the ruled.

11 This also applies to the restricted franchise model.

12 See Benz and Stutzer 2004: 33-4. 


\section{Kristian Skagen Ekeli}

The sub-majority rule model can be regarded as a future-oriented system of checks and balances, the purpose of which is to guard future generations against myopic majority decisions that neglect their vital interest and needs. The main aim of the proposed procedural rights is to empower minorities of future-oriented legislators to function as watchdogs for posterity in present political debates and struggles. They grant a predefined numerical minority of future-oriented legislators, who are elected and accountable through periodic elections, the power to police and control myopic majorities in the legislature. More precisely, the sub-majority rule model has an important power-checking function, in the sense that it can prevent the process of decision-making about issues affecting posterity from being subject to the immediate and unlimited control of myopic majorities of legislators. This power-checking function is absent in the restricted franchise model primarily because the F-representatives do not have the power to delay the process of legislation. Thus, an important advantage of the submajority rule model is that it gives future-oriented minorities of legislators more (real) political power to control and govern legislative processes than Dobson's F-representatives. As compared to Dobson's model, the submajority rule model provides a better and more effective future-oriented system of checks and balances.

The sub-majority rule model constitutes a future-oriented system of checks and balances that also functions as a horizontal accountability mechanism-in the sense that future-oriented minorities are enabled and empowered to monitor, control, and impose costs on myopic majorities in order to induce them to act in the best interest of posterity. The costs I have in mind here are the following.

(a) Compared with majority rule voting, both sub-majority rules create increased decision-making costs, that is, the costs (or time and effort) of securing or negotiating agreement on collective action. Typically, decision-making costs increase as increasingly large majorities are required. Both sub-majority rules and supermajority rules (e.g. a twothirds or a three-quarters majority) have higher decision-making costs than majority rule, since they make it more difficult to negotiate agreement on collective decisions.

(b) Devices such as delays and referendums are time-consuming, and moreover will create opportunity costs, that is, the cost of something (e.g. postponing a decision) in terms of an opportunity forgone and the benefits that could have been received from that opportunity. In many situations, majorities or groups of legislators might have strong incentives to avoid these costs, and this can encourage majorities to take seriously the views of future-oriented minorities. 
With regard to democratic accountability, it is also noteworthy that the submajority rules can have an accountability-forcing effect-that is, they give the predefined minorities the ability and right to force the majority to make a highly visible final decision on certain issues or laws, rather than disposing of the issue in some less prominent fashion. ${ }^{13}$

\subsubsection{Problems Facing the Sub-Majority Rule Model}

At this point, I will present three problems facing the sub-majority rule model that must be taken into account in order to assess the desirability of my proposal. The first can be termed the problem of a permanent myopic supermajority. One can imagine circumstances where a myopic supermajority (i.e. a two-thirds majority) is more or less permanent in the legislature so that it is practically impossible for future-oriented minorities to come into a position where they can use the proposed procedural rights. Under such circumstances, the value of the sub-majority rule model is seriously undermined.

The sub-majority rule model is also open to the problem of strategic abusesthat is, the proposed procedural rights can be abused by minorities for strategic or egoistic reasons. It might be tempting for a minority-who are not concerned for the well-being of future generations-to require for instance a delay in the hope that a bill they dislike or oppose would never be passed. In order to analyse how the problem of strategic abuses affects the desirability of the sub-majority rule model, it is worth keeping the following considerations in mind. First, the requirement that the minority has to present a prima facie case for demanding a delay or a referendum will presumably reduce the danger of strategic abuse, because it would make it difficult for a strategically motivated minority to come up with cogent public justifications for demanding delays or referendums for the sake of future generations. Second, constitutional courts have, as mentioned, the power to reject a delay or a referendum in cases where they believe that a minority is abusing the sub-majority rules for strategic reasons. Third, minorities who more or less openly abuse the suggested devices will expose themselves to the risk of being punished during elections. Fourth, even if certain minorities abuse the procedural rights, the sub-majority rules can in such cases create a more thorough and future-oriented process of deliberation about important intergenerational issues.

Finally, one can object that the proposed sub-majority rules face problems of democratic legitimacy - that is, problems related to the rightful democratic exercise of coercive political power. The main reason for this is that the

\footnotetext{
13 See also Vermeule 2005: 79.
} 


\section{Kristian Skagen Ekeli}

sub-majority rules have a counter-majoritarian character, in the sense that they give a minority of legislators the power to impede the will of the majority. This raises the question of whether the counter-majoritarian character of the sub-majority rules is problematic in view of requirements of democratic legitimacy. In order to consider this question, it is important to keep in mind the following considerations and ideas. ${ }^{14}$ First, the sub-majority rule model implies that majority rule should be used for final substantive decisionsthat is, the passage and defeat of legislation in legislatures and referendums. The sub-majority rules are only used for procedural matters. They are primarily used to set agendas for deliberation and voting (through majority rule).

Second, it is, on the one hand, a widely held assumption in political and democratic theory that democratic legitimacy does not require that the process of decision-making in legislatures should be subject to the immediate and unlimited control of majorities. On the other hand, it is a common assumption (especially in deliberative democratic theory) that the legitimating force of majority rule decisions is altered after a process of careful and well-informed deliberation. The idea is that there is an important difference between the counting or aggregation of judgements (or preferences) before and after a process of deliberation, because deliberation can create or promote what Melissa Schwartzberg calls 'judgments worth counting or aggregating'. ${ }^{15}$ A central aim of the proposed sub-majority rules is precisely to create judgements worth counting through majority rule in legislatures and referendums.

Third, one can argue that democratic legitimacy requires institutions or procedures designed to promote careful and well-informed deliberation in order to show respect for all those who are significantly affected by majority rule decisions-including future generations who are voiceless and vulnerable, since they cannot influence present decision-making processes. The idea is this. If a group of persons makes a majority rule decision without a prior process of deliberation where alternative courses of action and their impact on various affected parties are considered carefully or seriously, then the decisionmakers do not treat those affected with respect, and the legitimacy of the decision is significantly undermined. In this connection, the sub-majority rules can enhance the democratic legitimacy of majority rule decisions.

\subsection{Conclusion}

In this chapter, I have considered two alternative models for political representation of future generations. On the one hand, I have argued that Dobson's

${ }^{14}$ In Ekeli (2009), I discuss other aspects of the democratic legitimacy of the sub-majority rules.

15 See Schwartzberg (2014). See also Ekeli 2007b: 97-9. 
restricted franchise model has some interesting advantages compared with the status quo (i.e. existing representative democratic institutions), but that his model faces some important problems. On the other hand, it has been argued that the sub-majority rule model provides more effective and desirable political tools to represent and protect future interests than Dobson's model. ${ }^{16}$

\section{Bibliography}

Benz, Matthias, and Stutzer, Alois. 2004. 'Are Voters Better Informed When they Have a Larger Say in Politics?' Public Choice, 119(1-2): 31-59.

Dobson, Andrew. 1996. 'Representative Democracy and the Environment', in W. Lafferty and J. Meadowcroft (eds), Democracy and the Environment (pp. 124-39). Cheltenham: Edward Elgar.

Ekeli, Kristian Skagen. 2005. 'Giving a Voice to Posterity: Deliberative Democracy and Representation of Future People.' Journal of Agricultural and Environmental Ethics, 18(5): 429-50.

Ekeli, Kristian Skagen. 2007a. 'Green Constitutionalism: The Constitutional Protection of Future Generations.' Ratio Juris, 20(3): 378-401.

Ekeli, Kristian Skagen. 2007b. 'How Difficult Should it Be to Amend Constitutional Laws?' Scandinavian Studies in Law, 52: 79-101.

Ekeli, Kristian Skagen. 2009. 'Constitutional Experiments: Representing Future Generations through Sub-Majority Rules.' Journal of Political Philosophy, 17(4): 440-61.

Schwartzberg, Melissa. 2014. Counting the Many: The Origins and Limits of Supermajority Rule. Cambridge: Cambridge University Press.

Urbinati, Nadia. 2000. 'Representation as Advocacy: A Study of Democratic Deliberation.' Political Theory, 28(6): 758-86.

Vermeule, Adrian. 2005. 'Sub-Majority Rules: Forcing Accountability upon Majorities.' Journal of Political Philosophy, 13(1): 74-98.

\footnotetext{
16 I would like to thank Brian Garvey, Iñigo González-Ricoy, Axel Gosseries, Oluf Langhelle, Kjartan Koch Mikalsen, and Camilla Petterson for valuable comments and discussions. Thanks also go to two anonymous referees.
} 